\title{
Preventing Evaporation Products for High-Quality Metal Film in Directed Energy Deposition: A Review
}

\author{
Kang-Hyung Kim ${ }^{1}{ }^{\mathbb{D}}$, Chan-Hyun Jung ${ }^{2}$, Dae-Yong Jeong ${ }^{2}$ and Soong-Keun Hyun ${ }^{1,2, *}$ \\ 1 Program in Metals and Materials Process Engineering, Inha University, Incheon 22212, Korea; \\ ds2pav@hotmail.com \\ 2 Department of Materials Science and Engineering, Inha University, Incheon 22212, Korea; \\ changus0100@gmail.com (C.-H.J.); dyjeong@inha.ac.kr (D.-Y.J.) \\ * Correspondence: skhyun@inha.ac.kr; Tel.: +82-32-860-7547; Fax: +82-32-862-5546
}

check for updates

Citation: Kim, K.-H.; Jung, C.-H.; Jeong, D.-Y.; Hyun, S.-K. Preventing Evaporation Products for High-Quality Metal Film in Directed Energy Deposition: A Review. Metals 2021, 11, 353. https://doi.org/ $10.3390 /$ met11020353

Academic Editor: Joel Andersson

Received: 14 January 2021

Accepted: 16 February 2021

Published: 19 February 2021

Publisher's Note: MDPI stays neutral with regard to jurisdictional claims in published maps and institutional affiliations.

Copyright: (c) 2021 by the authors. Licensee MDPI, Basel, Switzerland. This article is an open access article distributed under the terms and conditions of the Creative Commons Attribution (CC BY) license (https:// creativecommons.org/licenses/by/ $4.0 /)$.

\begin{abstract}
Directed energy deposition (DED), a type of additive manufacturing (AM) is a process that enables high-speed deposition using laser technology. The application of DED extends not only to $3 \mathrm{D}$ printing, but also to the 2D surface modification by direct laser-deposition dissimilar materials with a sub-millimeter thickness. One of the reasons why DED has not been widely applied in the industry is the low velocity with a few $\mathrm{m} / \mathrm{min}$, but thin-DED has been developed to the extent that it can be over $100 \mathrm{~m} / \mathrm{min}$ in roller deposition. The remaining task is to improve quality by reducing defects. Thus far, defect studies on AM, including DED, have focused mostly on preventing pores and crack defects that reduce fatigue strength. However, evaporation products, fumes, and spatters, were often neglected despite being one of the main causes of porosity and defects. In high-quality metal deposition, the problems caused by evaporation products are difficult to solve, but they have not yet caught the attention of metallurgists and physicists. This review examines the effect of the laser, material, and process parameters on the evaporation products to help obtain a high-quality metal film layer in thin-DED.
\end{abstract}

Keywords: cavitation bubble; keyhole; nanoparticles; fume; spatter

\section{Introduction}

Directed energy deposition (DED) is an additive manufacturing technology (AM) used to manufacture 3D structures. The process can also be used to produce 2D deposition with dissimilar material deposition technology that forms a sub-millimeter coated layer. Thin-DED is particularly suitable to replace hexavalent chromium plating [1,2], which is very harmful to the human body. Among the other alternative techniques, plasma spray and high-velocity oxygen fuel (HVOF) spray have been strong candidates to replace chromium plating for over twenty years, but they are still incomplete because of low bonding strength. Besides, flame spraying with fusing or detonation-gun (D-gun) shows the strength of metallurgical bonding, but they are difficult to replace in the industry due to the expensive process cost and difficulty of uniform and thin deposition. On the other hand, DED can achieve high bonding strength similar welding to fix delamination failure, which is persistent in plated and thermal sprayed layers, and also has an important industrial significance owing to the high degree of freedom in material selection and deposited thickness.

Common defects in powder AM include porosity due to LOF (lack of fusion) or gases and cracks caused by differences in thermal expansion during cooling [3-7]. On the other hand, it is difficult to manufacture porosity-free or crack-free products in the manufacturing stage using current technologies. Efforts to detect defects during the process or after completion by non-destructive testing, such as XCT (X-ray computed tomography) $[3,5]$ and acoustic emission [4], are continuing. In the DED process, a metal powder or wire is supplied while focusing the laser on the base metal surface to form a 
melt pool by a reaction with the laser light and laminate it to a height of several millimeters. In that respect, it is similar to cladding $[8,9]$.

To replace plating or thermal spray coating, it is necessary to deposit in a thin layer while preserving the original shape of the base metal, which is difficult using the general DED method. Figure 1 presents a schematic diagram comparing PBF (Powder Bed Fusion) and DED, which are typical processes in metal AM, with thin-DED. Figure 1a is PBF, which is formed by laser irradiation of a thin layer of metal powder and melting the desired area layer by layer, and Figure $1 \mathrm{~b}$ is DED, which produces a melt pool with a laser beam on the base metal, followed by the supply of a metal wire or powder to the melt pool with deposition in millimeter units. Figure $1 \mathrm{c}$ is a thin-DED that combines the advantages of both processes. In thin-DED, while the incident laser beam supplies powder to a twodimensional surface of the workpiece, a thin layer of 50-300 micrometers is deposited per scan. Unlike general DED, thin-DED has a unique characteristic that the base metal is barely diluted. Only the powder is fused, so there is virtually no diluted bonding layer or little penetration.

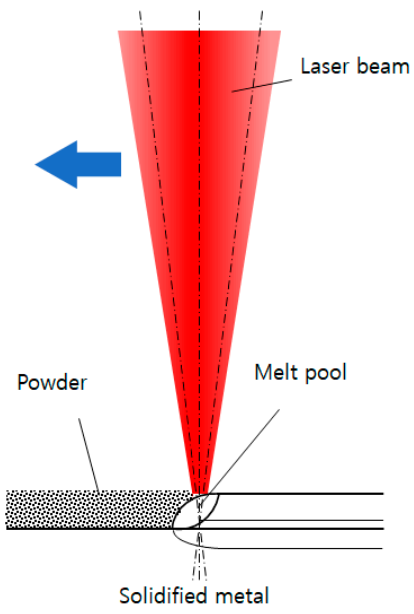

(a)

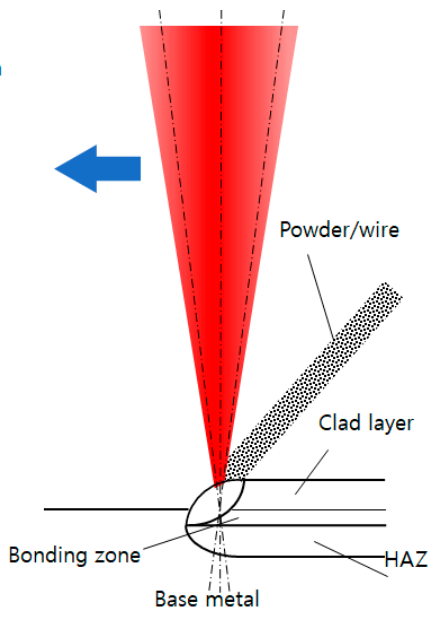

(b)

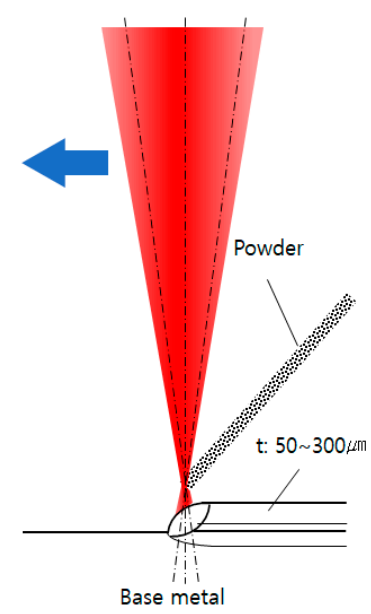

(c)

Figure 1. Schematic diagrams of metal AM processes: (a) PBF; (b) DED; (c) thin-DED.

In the general DED process, when the evaporated metal expands to form bubbles, the internal vapor pressure of the bubbles increases, and the bubbles burst to release evaporation products. The volatilized nanoparticles of evaporated metal are generally called a fume [10]. The massive particles resulting from the agglomeration of evaporated nanoparticles to a size of several hundred micrometers are called spatter [11-13]. Fumes are small enough to float in the atmosphere or hinder the reaction between the material and the laser and have very high reactivity with the human body or melt. Therefore, it harms the health of workers [14] and degrades the quality of the deposited layer due to a photochemical reaction with the laser, porosity, change in chemical composition, and impurities. Spatter contaminates tracks on the workpiece, causing various defects, such as increased roughness, porosity, contamination of the nozzle surface, decreased fatigue strength, decreased thermal conductivity, and low fluidity. In the general DED or cladding process, the solidification time is long, so there is some time for the dissolved gas absorbed in the melt to release. Since the melt pool is deep and wide, any spatter attached to the surface is also remelted, so there are few problems caused by evaporation products. In thin-DED, however, the time to solidify the deposited layer is very short so that fumes can become trapped in the melt and produce pores. Furthermore, pores can be formed in the gaps as molten powders are again laminated on the massive spatter.

In this study, to manufacture a high-quality metal thin film by a thin-DED process, the mechanism of forming evaporation products by a laser, the reaction with the laser according to the properties of powder materials, and the influence of the process parameters 
were investigated in depth, shown in Table 1. By adjusting the laser density and process parameters based on these findings, it will be possible to prevent evaporation products and form a high-quality metal film layer in the thin-DED process.

Table 1. Preventive methods of fume and spatter in DED.

\begin{tabular}{|c|c|c|c|}
\hline Relevant DED Defects & Major Factors & Sub-Factors & Preventive Measures \\
\hline \multirow{5}{*}{$\begin{array}{l}\text { Lower corrosion resistance, } \\
\text { decreased fatigue strength, } \\
\text { inner crack, surface crack, } \\
\text { surface dimple, porosity, high } \\
\text { roughness, uneven hardness, } \\
\text { decreased laser energy } \\
\text { efficiency, lower fluidity of } \\
\text { melt. }\end{array}$} & Material & $\begin{array}{l}\text { Absorptivity, small powder } \\
\text { size }(<15 \mu \mathrm{m}) \text {, presence of low } \\
\text { melting point elements or low } \\
\text { vaporization temperature } \\
\text { elements }\left(<2000^{\circ} \mathrm{C}\right) \text {, presence } \\
\text { of carbon or boron, eutectic } \\
\text { reaction, low wettability, } \\
\text { characteristics of base metal. }\end{array}$ & $\begin{array}{l}\text { Adjustment of laser power, irradiation } \\
\text { angle, surface condition of the powder } \\
\text { and base material. } \\
\text { Appropriate choice of suitable powder } \\
\text { size, addition of compound-forming } \\
\text { refractory components }(\mathrm{Nb}, \mathrm{Ta}, \mathrm{W}, \mathrm{Zr}) \text {. } \\
\text { Replacement to very low carbon- and } \\
\text { boron-contained powder. }\end{array}$ \\
\hline & Source Laser & $\begin{array}{l}\text { Laser type, laser power } \\
\text { density, beam divergence, } \\
\text { duration time, wavelength of } \\
\text { laser. }\end{array}$ & $\begin{array}{l}\text { Adjustment of laser power, powder } \\
\text { feed rate. } \\
\text { Selection of CW laser, top-hat mode } \\
\text { beam, larger diameter beam, } \\
\text { rectangular beam, or defocusing. }\end{array}$ \\
\hline & Working Condition & $\begin{array}{l}\text { Hatches distance, powder } \\
\text { feed rate, scanning velocity, } \\
\text { nozzle distance, cooling rate, } \\
\text { layer thickness, humidity, } \\
\text { vibration. }\end{array}$ & $\begin{array}{l}\text { Redefining new conditions from single } \\
\text { track experiments. } \\
\text { Adjustment of hatches distance, } \\
\text { powder feed rate, scanning velocity, } \\
\text { nozzle distance, cooling rate, and layer } \\
\text { thickness. } \\
\text { Usage of air conditioner, and vibration } \\
\text { absorber. }\end{array}$ \\
\hline & Assist gas & Gas pressure, kind of gas. & $\begin{array}{l}\text { Appropriate pressure for complete air } \\
\text { shielding. } \\
\text { Replacement of nitrogen or mixed } \\
\text { argon-nitrogen gas to pure inert gas } \\
\text { (argon or mixed argon-helium). }\end{array}$ \\
\hline & Laser Focusing & $\begin{array}{l}\text { Beam mode, beam shape, } \\
\text { nozzle design, focal length, } \\
\text { focused on the base material } \\
\text { surface. }\end{array}$ & $\begin{array}{l}\text { Appropriate choice of top-hat mode } \\
\text { beam, larger diameter beam, } \\
\text { rectangular beam, defocusing, inclined } \\
\text { laser beam. }\end{array}$ \\
\hline
\end{tabular}

\section{Generation of Evaporation Products}

\subsection{Evaporation by Laser}

In the past, fumes were understood as the vaporization of solid metals by high energy. In recent years, the basic mechanism of fume generation involves the evaporation of elements and oxides by plasma from a superheated melt. The fume is comprised of nanoparticles from the metallic vapor phase [15-17]. Metallic nanoparticle fumes are generated by various physicochemical methods, such as laser, electron beam, ion beam, plasma ionization, electromagnetic wave, arc discharge, combustion, spray pyrolysis, physical or chemical vapor deposition, but an analysis of the process is not simple.

Since Anisimov analyzed metal vapor motion in a vacuum by hydrodynamics in 1968 [18] molecular dynamics (MD), hydrodynamics (HD), and direct simulation Monte Carlo (DSMC) methods have been performed to understand the plasma formation and the plume behavior, making significant progress in comprehending the stages of evaporation [19-47]. Recently, the stage of the plume generation has been observed directly by shadowgraphy in laser confocal scanning microscopy (LCSM) [48,49] and high-speed scanning small-angle X-ray scattering (SAXS) [50,51]. 
The released fumes interrupt the laser energy transfer to the additive powder and base metal and often enter the deposited layer as impurities. Furthermore, agglomerated massive particles are released as spatter, contaminating the nozzle and the base metal surface.

\subsection{Evaporation Mechanism on Thin-DED Process}

In the thin-DED process, when high-speed photons hit the base metal surface as increased light intensity, free electrons of metal atoms absorb the energy to generate the laser-induced plasma [52]. At the focus of the laser beam, the base metal is heated rapidly to form a melt pool and releases nanoparticles to the atmosphere during bubble collapse through the bubble expansion and plasma plume stages [50]. When a keyhole forms in the melt pool, robust hydrodynamic melt flow rises vertically due to the recoil pressure and the Marangoni effect $[45,53,54]$. This results in the release of nanoparticles and several hundred micrometers sized spatter particles. All reactions from plasma formation to nanoparticle release occurred within only a few tens to hundreds of microseconds [55]. This occurs more frequently in pulsed-wave laser than continuous-wave laser because of the high peak power [56].

\section{Influence of Laser Characteristics}

The high energy laser is difficult to control in the DED process because it reacts with the deposition material and base metal within tens to hundreds of microseconds. Moreover, the loss of the delivery system, cooling system, optical lens, and conversion system vary greatly depending on the source laser. Furthermore, the efficiency varies greatly depending on the deposition material and the surface condition of the base metal. The shape of the deposition material is an important parameter. The drop size of the molten powder is finer than that of a molten wire drop, allowing uniform and thin deposition. General DED is melted by the photochemical reaction of a laser, base metal, and deposition material. Thin-DED involves a reaction mainly between the laser and the powder, minimizing melt pool formation on the base metal, resulting in a thin and uniform deposited layer. The thickness of the deposited layer obtained by thin-DED is 50-300 micrometers, which is quite thin, and there are little bonding zones caused by dilution. For this, cavitation bubbles and keyhole phenomena must be suppressed. Precise control of the powder feed rate from the nozzle, laser power adjustment, scanning velocity, and the location where the powder and laser meet are key parameters in the process.

\subsection{Laser-Induced Cavitation Bubble}

Cavitation is a phenomenon in which vapor bubbles are generated in a liquid when the saturated vapor pressure decreases with increasing temperature or velocity. In thin-DED, cavitation bubbles can be formed by the laser plasma when the fluid pressure or the fluid velocity of the melt increases rapidly [50].

Figure 2 presents a conceptual diagram showing how cavitation bubbles are generated and grown by laser irradiation, nanoparticles are released as fumes, and aggregated massive particles are released as spatter. Initially, a cavitation bubble, which is in the form of a nano-scale hemisphere (I), expands to a millimeter size [50]. The jet flow velocity of nanoparticles along the plasma plume rises perpendicularly to the surface of the base metal and passes through a conical shape (II) to a pointed top. It becomes form (III). Stauss et al. explained (Figure 3) the step-by-step process of emitting nanoparticles after the expansion of cavitation bubbles during laser ablation. Since the cavitation bubble interface is not a material film, it is formed only by the difference in pressure and density. Some nanoparticles may escape from the cavitation bubble into the surrounding fluid [46]. 


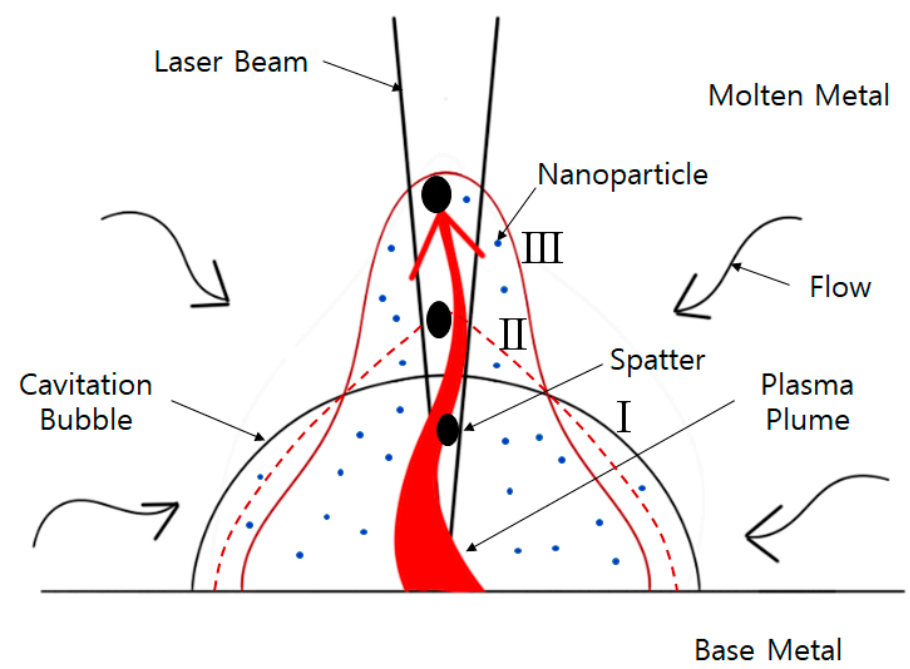

Figure 2. Modified Ibrahimkutty's conceptual diagram for fluid flow in the cavitation bubble, immediately before the generation of evaporation products, bubble stages: hemispherical cavitation bubble (I) expansion of a cone shape bubble (II, dotted line) ejection of a spin top shape bubble (III) [50].

$$
t<0 \quad t=0-\tau
$$

Before laser penetration Absorption of the laser

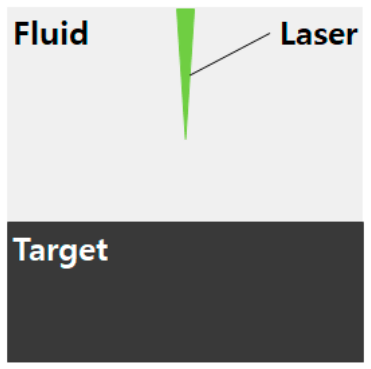

$$
t=10^{-10}-10^{-7} s
$$

Expansion and quenching of plasma plume
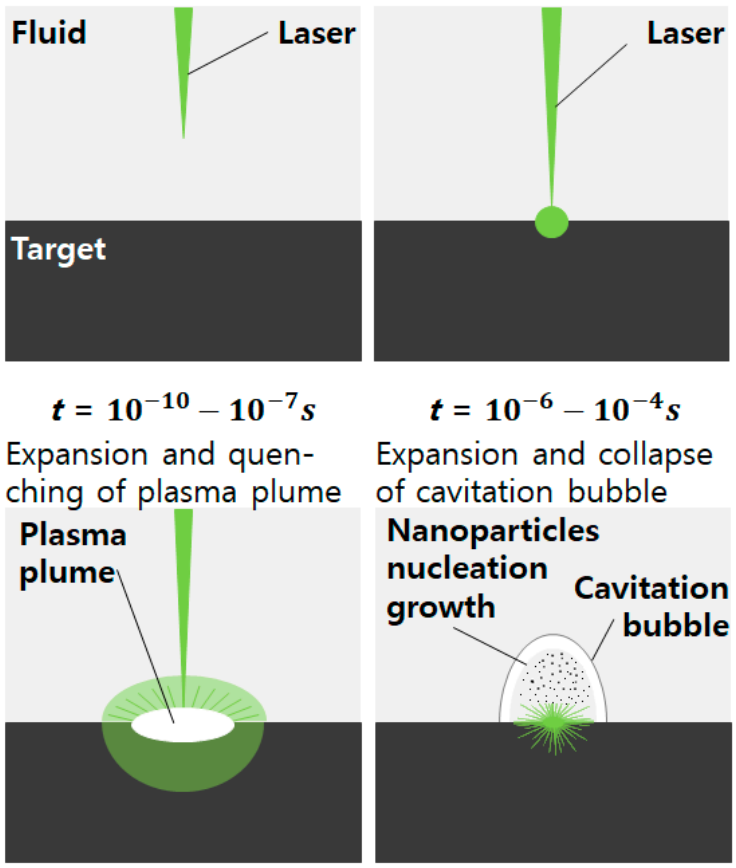

$$
t=10^{-6}-10^{-4} s
$$

Expansion and collapse of cavitation bubble

\section{Nanoparticles} nucleation growth

Cavitation bubble

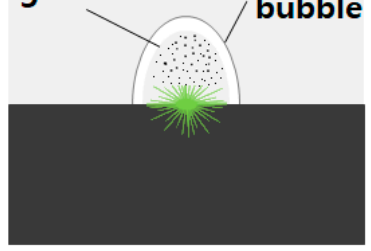

$$
t=10^{-12}-10^{-10} s
$$

Detachment of the ablated material

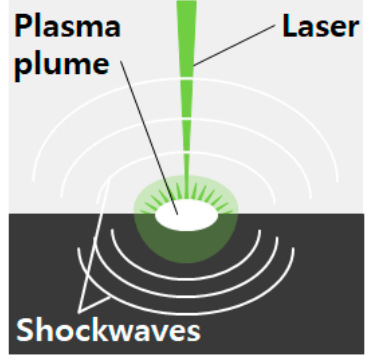

$$
t>10^{-4} s
$$

Slow growth and agglomeration of NPs

Agglomerated nanoparticles

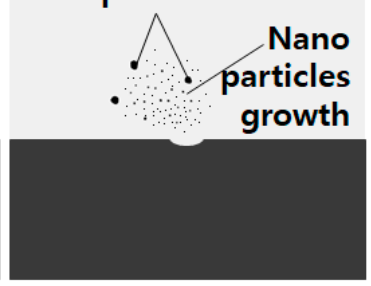

Figure 3. Rapid heating by a laser beam and subsequent plasma formation leads to the formation of cavitation bubbles, then vaporization by nanoparticle (NP) nucleation and growth in a pulsed laser, at $\mathrm{t} \sim 10^{-6}-10^{-4} \mathrm{~s}$. (Modified from Stauss' nanomaterial nucleation diagram [46]).

Muneoka et al. described the following six stages in more detail: plasma formation (phase I), cavitation bubble expansion (phase II), bilayer cavitation bubble expansion (phase III), contraction (phase IV), stagnation (phase V), and cavitation bubble collapse with nanoparticle release (phase VI) [51]. Ibrahimkutty et al. observed the moments at 320 microseconds (phase VI) in which the bubble collapse after the rise of the plasma plume inside the cavitation bubble, as shown in Figure 4 by X-ray [50]. At that moment, the evaporation products are released into the atmosphere. 

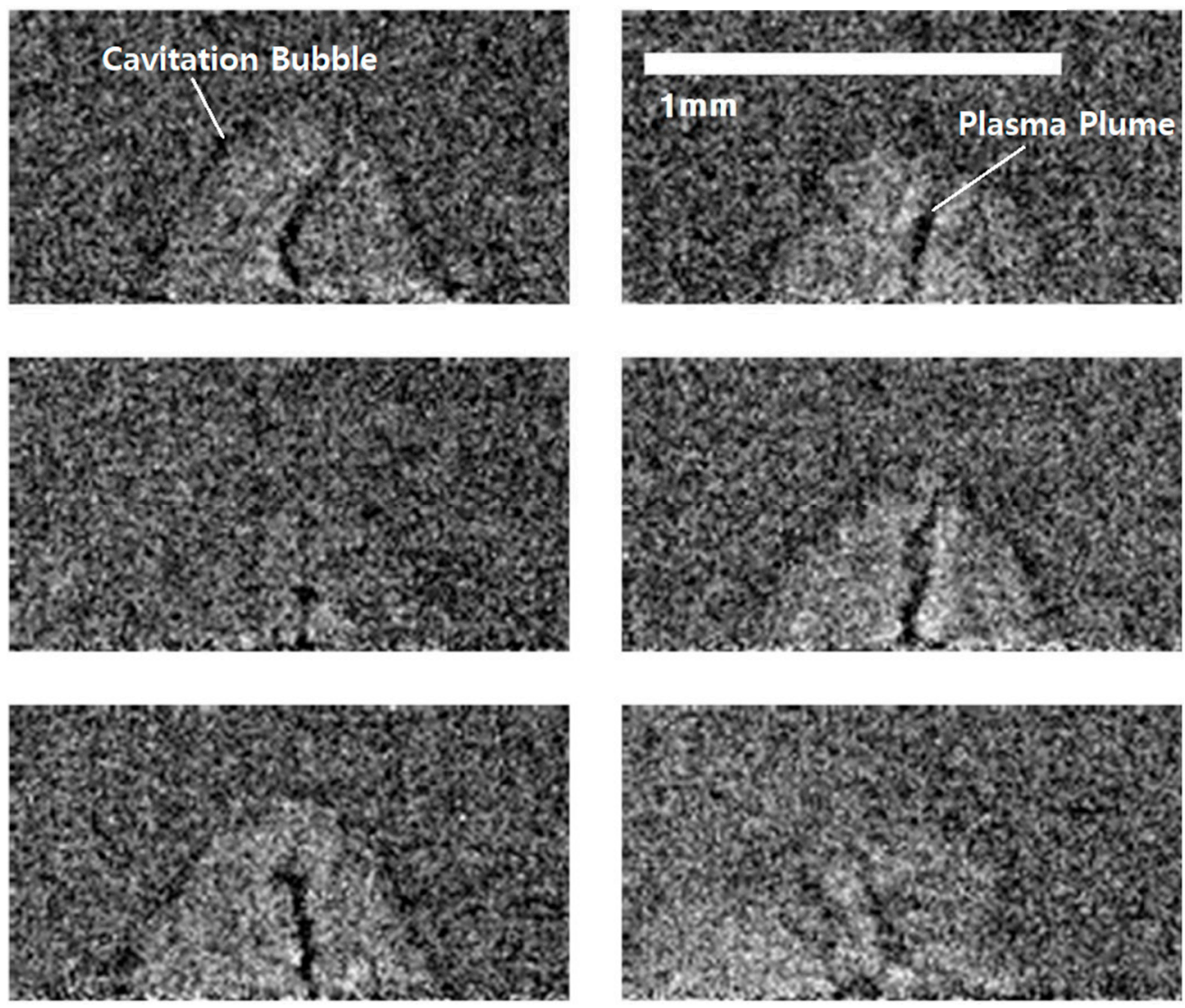

Figure 4. Representative individual radiographs from single laser shots at a fixed delay of ca. 320 microseconds, shows the variability of the plasma plume of phase VI (cavitation bubble collapse) (Reused with permission from ref. [50], copyright (2015), Nature).

\subsection{Prevention of Cavitation Bubble}

The temperature at the center of the high-power laser beam is 2200-3000 K [57,58], sometimes above $4000 \mathrm{~K}[45,55,59,60]$, and plasma is formed at the beam focus [50]. Occasionally, a low absorptivity material melts slightly even in an intense laser beam at first. Still, the melt is suddenly superheated as the absorptivity rises rapidly in a locally melted area. For example, the absorptivity of an aluminum alloy is only $5-15 \%$, but that of steel exceeds $40 \%$ in an Nd:YAG laser with a one-micrometer wavelength [61]. Therefore, it is important to work rapidly with a high energy density for aluminum alloys [62].

The absorptivity of laser energy is related to the material composition, the incident laser angle, and the laser wavelength [61]. The angle is the relative range between the laser nozzle and the base metal. The energy wave ( $\mathrm{P}$ wave) of a laser is absorbed only $25 \%$ at an incident angle of $70^{\circ}$ to a ferrous material between the laser nozzle and the base metal. On the other hand, the absorptivity increases significantly to $70-82 \%$ at $87^{\circ}$ or higher, and a one-micrometer wavelength $\mathrm{Yb}$-doped fiber laser has high absorptivity in the $70-85^{\circ}$ range. The ten-micrometer wavelength $\mathrm{CO}_{2}$ laser has the highest absorptivity at 85-88.5 [61].

Therefore, the energy density can be adjusted by changing the incident laser angle [63]. In this adjusted area, the laser absorptivity changes due to the anisotropic absorptivity of the base metal surface [64], and cavitation is suppressed. Another way is to adjust the laser beam scanning velocity [65] or focus position [66-68], and a pulsed laser is desirable to change as a top-hat mode or a continuous wave laser (CW laser).

\subsection{Prevention of Keyhole}

A keyhole often forms at high scanning velocities and high ambient pressures [69] when the focus is deep with high power or a Gaussian beam. When the laser energy density 
is higher than the thermal conductivity, keyholes are formed by an interaction between the absorbed laser energy and the free electrons of the metal. At this time, the electrons of the valence band transfer to the conduction band, and the migrating electrons interact with the metallic bonds, lattice strain, defect, imperfection, and potential perturbation [70]. A CW laser with a top-hat profile [71] or rectangular beam [72] laser is better for preventing keyhole formation.

Katayama's illustration and Kaplan's diagram are useful for understanding keyhole formation. Katayama reported that a keyhole is formed by recoil pressure due to evaporation [70], and Kaplan described in detail the keyhole in seven phases: (a) Melt flow redirected to pass around the keyhole, (b) Marangoni flow driven by surface tension gradients, (c) redirected flow that can cause spatter, (d) humping caused by accumulating downstream flow, (e) stagnation point for accelerated flow, (f) inner eddy, and (g) keyhole front melt film flow downwards by boiling recoil pressure, which is illustrated in Figure 5 [73].

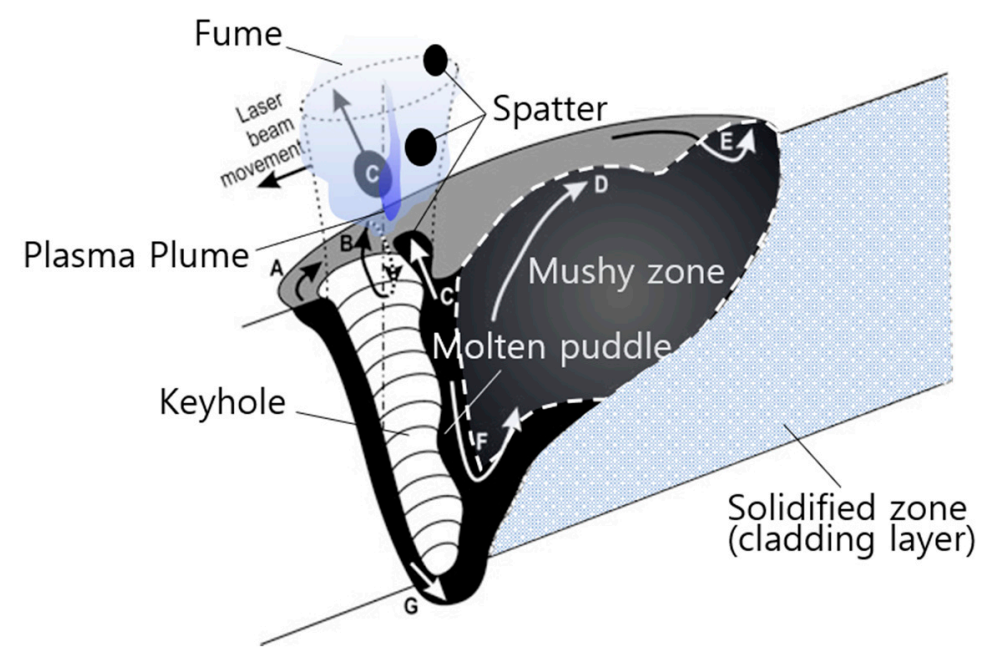

Figure 5. Modified schematic diagram of Kaplan's and Katayama's illustration, depicting the evaporation products formation by laser [70,73] ((Reproduced with permission from ref. [73], copyright (2017), Springer Nature)).

According to Khairallah et al., even in the shallow deposition of a PBF simulation, recoil pressure occurs similar to a keyhole because of the high temperature, and strong Marangoni convection occurs due to the surface tension during cooling [59]. Gunenthiram et al. examined spatter generation with a high-speed camera to understand better the spatter generation process according to the power change [62]. Unlike the laser welding process, the thin-DED process needs to reduce keyhole and spatter formation by avoiding a pulsed wave or Gaussian beam that makes deep and narrow melt pools.

\subsection{Position of the Laser Beam Focus}

The focus of the laser beam is influential because it is the highest energy area. When the defocus distance increases by moving the beam's focus slightly up or down on the base metal surface, the energy density of the melt pool decreases because the laser irradiation area widens [67]. Moreover, powder melt temperature decreases, which suppresses the generation of evaporation products.

Figure 6 shows the defocus in laser drilling, which explains the effect of the beam focus due to a focus shift and angle in Figure 6a-i [53,74]. For examples of Figure 6h,i, the influence appears similar to the defocus when the laser irradiation angle is changed. $\mathrm{Li}$ et al. reported that spatter was suppressed in the keyhole of laser welding when the focus position moved downward from the base metal surface [69]. 


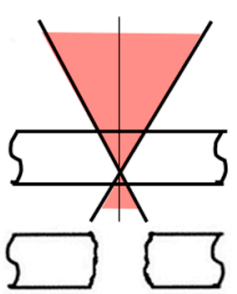

(a)

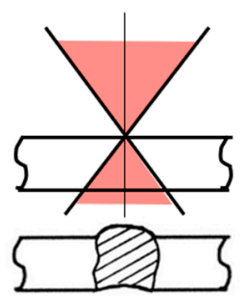

(d)

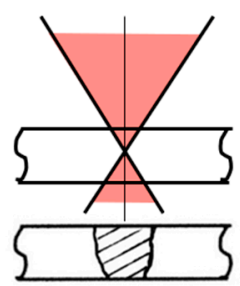

(g)
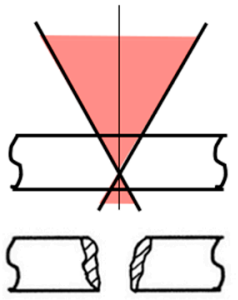

(b)

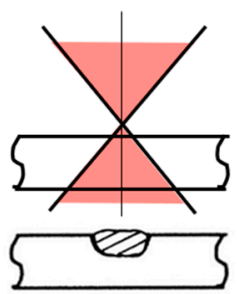

(e)

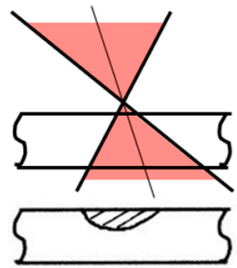

(h)

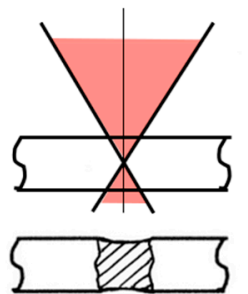

(c)

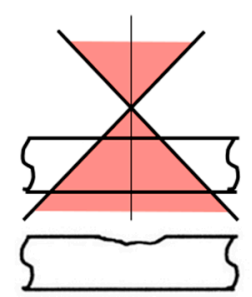

(f)

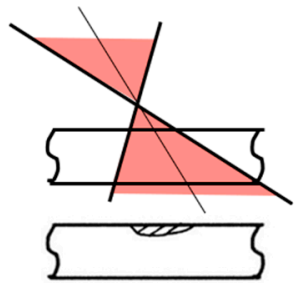

(i)

Figure 6. Effects of the beam focus position and beam angle on the focus depth and shape of laser drilling (a-i) (modified from Yeo's illustrations) [53,74].

In thin-DED, if the focus is on the surface of the base metal, the depth of the melt pool may become too deep due to the high laser power density, which may damage the original shape. On the other hand, it may leave an incomplete deposition layer and pores when the laser power is decreased to avoid overheat. The deep melt pool problem can be solved in two ways. First, it decreases the depth of the melt pool shallower by applying a defocus while maintaining power. Second, when the powder is supplied to the upper point of focus, the temperature of the laser beam focus decreases, which lowers the melt pool temperature of the base metal.

\section{Influence of Powder Characteristics}

Powder characteristics such as the size, chemical composition, and surface condition of the powder particles have a great influence on moisture absorption from the atmosphere and reaction with the laser beam, so it is important to select a suitable particle for the DED process to prevent evaporation products.

\subsection{Powder Size and Chemical Composition}

The powder size and chemical composition are important factors. The small powder has high surface energy and a short time for melting, which can be superheated easily. Porous sintered powder or fine powder has a large specific surface area to volume ratio. Thus, the amount of atmospheric moisture adsorbed and the laser absorptivity is relatively high. Fine particles under five micrometers in the powder cannot settle on the melt pool and are blown away by the gas flow or often meet the laser beam to become a fume. Therefore, a particle size of $30-45 \mu \mathrm{m}$ is suitable for the high-power thin-DED process. The powder should have a similar thermal expansion coefficient to the mixed phases and a small difference in particle size distribution. 
Because a laser is an electromagnetic wave, the lattice $[70,75]$ condition and electron orbitals [76,77] vary according to the composition and absorptivity of the powder. Powders containing metal elements with a low evaporation point below $2000{ }^{\circ} \mathrm{C}$ or containing carbon or boron generate evaporation products easily and hinder the absorption of a laser on the base metal. When the chemical composition changes due to fume generation, it alters the melt fluidity, and thermal conductivity may cause the formation of pores or cracks in the coating layer. The compound-forming refractory components, niobium, tantalum, tungsten, and zirconium, are useful for improvement because they have vaporization points of $3000{ }^{\circ} \mathrm{C}$ or higher.

Evaporation is not determined merely by the melting point and vaporization point of the component. It depends on the eutectic reaction among atoms in the alloy or the formation of an intermetallic compound and the vapor pressure of the evaporated component. As an example, Figure 7 presents a comparison graph for evaporation of 304 stainless steel [78], where Figure 7a is the respective evaporation curves of iron, manganese, chromium, nickel, and Figure $7 \mathrm{~b}$ is the evaporation curves of the four elements in the alloy. Among the four elements, the vapor pressure of manganese is the highest, but the vapor pressure of manganese in the alloy is the lowest. According to Henry's law, the partial pressures determine the vaporization rate because the manganese content is less than $2 \%$ in 304 stainless steel. Iron and chromium are present in $70 \%$ and 18\%, respectively. On the other hand, neither carbon nor boron is presumed to follow Henry's law.
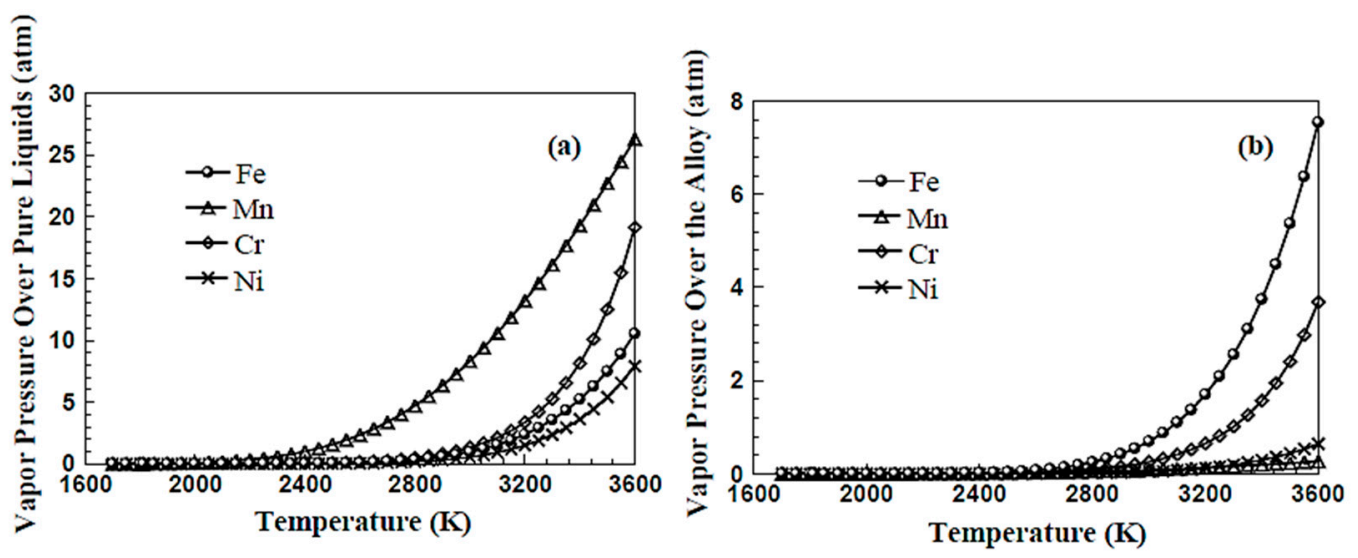

Figure 7. Equilibrium vapor pressures of the four alloying elements (a) over the respective pure liquids, and (b) over the alloy at different temperatures [78]. (Reused from ref. [78], copyright (2003), Sandia National Laboratories).

It is better to refer to the phase diagram rather than the Ellingham diagram to predict the presence of evaporation products. For example, regarding the Gibbs Energy of chromium carbides, many studies have reported that $\mathrm{Cr}_{23} \mathrm{C}_{6}$ is more stable than $\mathrm{Cr}_{7} \mathrm{C}_{3}$ or $\mathrm{Cr}_{3} \mathrm{C}_{2}$ in the Ellingham diagrams. On the other hand, these are different from the molten state because they present a solid-state range of 700-1300 ${ }^{\circ} \mathrm{C}$. In the $\mathrm{Cr}-\mathrm{C}$ phase diagram, however, the stability is $\mathrm{Cr}_{23} \mathrm{C}_{6}<\mathrm{Cr}_{3} \mathrm{C}_{2} \leq \mathrm{Cr}_{7} \mathrm{C}_{3}$ [79,80]. Berdnikov and Gudim and Vlasova et al. reported the evaporation point of chromium carbides in the order of $\mathrm{Cr}_{23} \mathrm{C}_{6}<\mathrm{Cr}_{7} \mathrm{C}_{3}<\mathrm{Cr}_{3} \mathrm{C}_{2}$ [81,82]. The powder containing chromium carbide has increased the vapor pressure of carbide when dissolved in $1527-1811^{\circ} \mathrm{C}$ according to the $\mathrm{C}-\mathrm{Cr}$ binary eutectic reaction [83] and Fe-Cr-C ternary eutectic reaction [84]. This presents the fume as oxidation [82] in the atmosphere. Despite this, there are few cases where refractory carbides, $\mathrm{NbC}, \mathrm{TaC}$, and $\mathrm{ZrC}$, evaporate below $3000{ }^{\circ} \mathrm{C}$ [85].

\subsection{Surface Condition of Powder}

The composition and surface condition of powder is closely related to the laser absorption rate. The powder is produced mainly by four processes, crushing, atomizing, agglomeration, and sintering after agglomeration; the surface condition of the powder is 
very influential in the thin-DED process. A hard and brittle powder could be obtained by crushing a bulk material. That is not used in the additive manufacturing process because of its polygonal and sharp edges. The alloy powder is manufactured mainly by atomizing, involving a molten metal spray with 10-50 MPa high-pressure gas or water. High melting point refractory carbide powders are usually produced by agglomeration with fine metal powders as binders and sintered to increase the density. Figure 8 shows the difference in surface morphology between the atomizing powder and agglomerated-sintering powder. The point to consider in powder selection is porosity in agglomerated powders. Another is a brittle phase by carbide dissolution in the binder metal [86]. Recently, plasma-atomized tungsten carbide powder [87-90] was used to prevent embrittlement of the cladding layer.
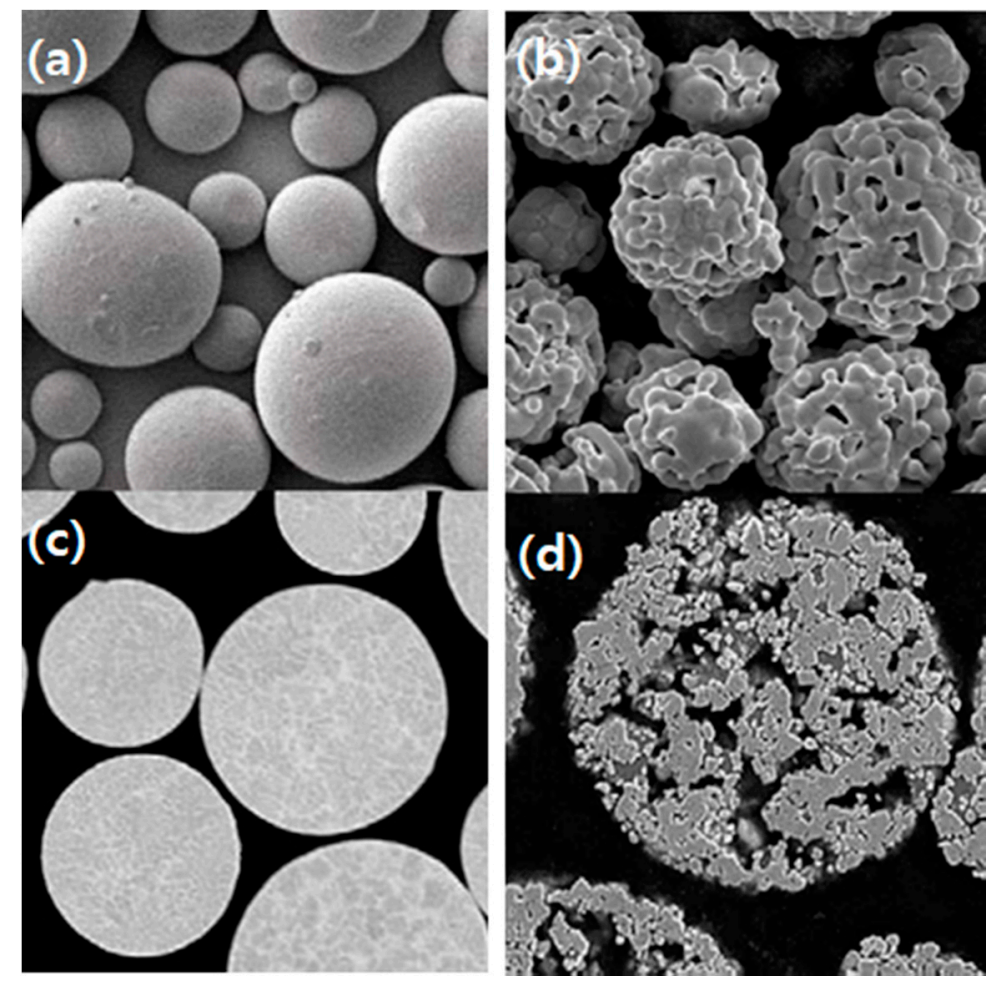

Figure 8. Powder morphology depicted in different manufacturing processes: $(\mathbf{a}, \mathbf{b})$ External surface; $(\mathbf{c}, \mathbf{d})$ Cross-section; $(\mathbf{a}, \mathbf{c})$ Metal alloy powder as gas atomized; $(\mathbf{b}, \mathbf{d})$ Regular carbide powder as agglomerated and sintered) [91]. (Reused from ref. [91], copyright (2018), Oerlikon Metco).

The wettability between the pair of base metal and deposition powder also has an influence. Insufficient wettability causes non-uniform deposition because of the different absorptivity between the deposited melt and the uncoated area. If the main compositions between the base metal and the deposition material are similar, the wettability by the similarity in physical properties is sufficient. When selecting a deposition material with a different main component from the base metal, a material with a similar thermal expansion coefficient is chosen.

The last factor is moisture adsorbed on the surface. Agglomerated and sintered powders or fine powders have high surface energy so that moisture can be adsorbed on the particle surface. Strongly adsorbed moisture is difficult to remove by heating or vacuum [92], and the surface generally tends to lower the surface energy by forming an oxide layer with moisture [93]. Most moisture adsorption is physical adsorption caused by weak van der Waals forces. Water molecules are difficult to remove by heating when chemical adsorption occurs by covalent bonding or ionic bonding with the reactive gases in porous powders or on the rough base metal surface [94,95].

As shown in Figure 9, chemical adsorption occurs because of the "image force", in which electrons on the oxygen atom side of the water molecule repel some electrons on the 
powder surface and attract positive charges $[96,97]$. The adsorbed moisture reacts rapidly during powder melting and produces a fume containing oxides $[15,98]$ and nitrogen oxides [99-103] that are harmful to the human body. Before use, powders should be dried in a heated oven for eight hours above the boiling point of water $\left(100{ }^{\circ} \mathrm{C}\right)$, cooled, and immediately charged into the hopper to avoid contact with the atmosphere.

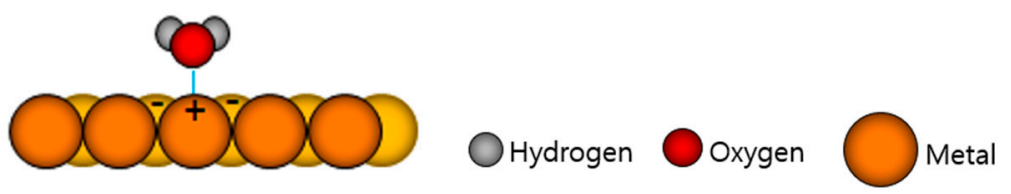

Figure 9. Example of a moisture particle adsorbed on metal by image force [97].

\section{Process Parameters}

\subsection{Powder Feed Rate}

Determining the suitable powder feed rate requires experiments. If the powder feed rate is too low, the melt pool is superheated and generates keyholes and cavitation bubbles. In contrast, if the powder feed rate is too high, the base metal is not heated uniformly, so the melt pool is not uniform and does not deposit appropriately.

For the experimental sequence, a specific range of the powder feed rates to the volume ratio was set, and the other parameters (power, scanning velocity, and hatch distance) were adjusted. Finally, the powder feed rate was fine-tuned to the desirable level.

\subsection{Scanning Velocity}

When increasing the scanning velocity on the base metal, the lack of powder should be considered. An increase in scanning velocity under the same powder feed rate means much more laser energy is supplied to the powders and base metal. Thus, base metal and powders can be superheated.

To maintain the powder feed rate while increasing the scanning velocity, the laser power must be reduced to achieve a constant energy density per powder unit weight. Indeed, when the scanning velocity increases, the deposited layer is better with an increase in the powder feed rate or a decrease in power density [104] because cavitation bubbles can form when the maximum temperature of melt increases. A uniform and thin deposited layer can be obtained under properly controlled process parameters, even high-speed thin-DED.

\subsection{Powder Supplying Position}

Unlike the usual DED of supplying powder to a focus, in thin-DED, the powder reacts with the laser beam first by supplying powder slightly above the focus or by a defocus. The remaining laser energy then reaches the base metal surface $[105,106]$. Thus, the laser energy to the melt pool is reduced, resulting in a thinner bonding zone, improved powder recovery, and faster deposition velocity.

\subsection{Shape of the Laser Beam}

The latest technology modulates a rectangular laser beam through a cylindrical lens array [107] or crossed Powell lenses [72]; combining it increases the productivity of the laser deposition process. A wide rectangular beam can allow uniform heating [108-111] compared to a Gaussian beam. Thus, the structure of the deposited layer has a uniform composition and dispersion strengthening by fine precipitates.

\subsection{Environmental Parameters}

Generally, the generation of evaporation products is accelerated if the thin-DED process is performed in an air environment. If the process atmosphere contains reactive gases, such as oxygen [112], nitrogen [99], sulfur [98,100], halogen group elements [113,114], or moisture [115-117], it accelerates the generation of evaporation products. In particular, 
nitrogen gas sometimes promotes the oxidation of carbide $[116,118]$ and the formation of nitrogen oxides [101] and nitrides [102]. The nitrogen radicals decomposed by the high energy of the laser beam become nitrogen oxides $\left(\mathrm{NO}_{\mathrm{x}}\right)[99,100]$, and the nitrogen oxides in contact with the laser beam again decompose to become reactive oxygen species and nitrogen oxide ions [103]. These reactive oxygen species oxidize the carbide of the powder. Therefore, when fumes are generated continuously, a shielding gas should be changed to an inert gas, argon, or helium without nitrogen. Due to an excessive shielding gas flow forming turbulence, the amount of laminar flow gas is appropriate for covering the laser and melt pool [119].

\section{Experimental Sequence of Thin-DED}

Thin-DED experiments can be performed in the sequence of a single-track and a multi-track. In the single-track experiment [120], the possibility of bonding between the base metal and the deposited powder could be investigated first, except for the effects of overlap, preheating, and post-annealing. The suitability of powder selection or process conditions can be determined by examining whether defects are generated according to the reaction between the powder and the laser beam.

When evaporation products form, the cause of the defect can be analyzed using the Ishikawa diagram. Figure 10 is a remake to prevent evaporation products in the thin-DED process by modifying the diagram reported by Yeo et al. [74]. Evaporation products can be avoided by choosing suitable material, further finely optimizing the parameters working condition, source laser, assist gas, and laser focusing.

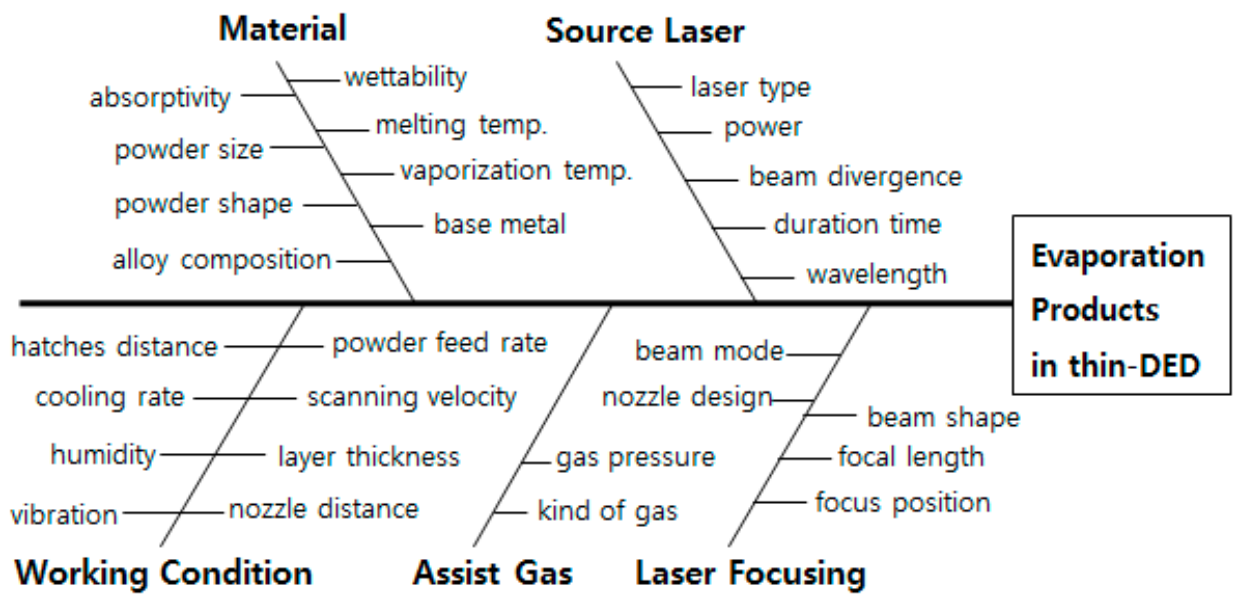

Figure 10. Ishikawa diagram showing the various parameters affecting the evaporation products in thin-DED (modified from Yeo's Ishikawa diagram) [74].

Figure 11 shows two experimental examples of single-track thin-DED. In Figure 11a, the laser power was low, and the base metal surface was not heated sufficiently. The wettability of the powder was also insufficient. Hence, the material did not deposit completely, and spatter was present at the beam boundary. Figure $11 \mathrm{~b}$ gives an example of good results on a single-track. Therefore, an experiment to control the hatch distance in a multi-track experiment can produce a better-deposited layer than a single-track [97]. Figure 12 shows a thin-DED multi-track experiment on rolls. 

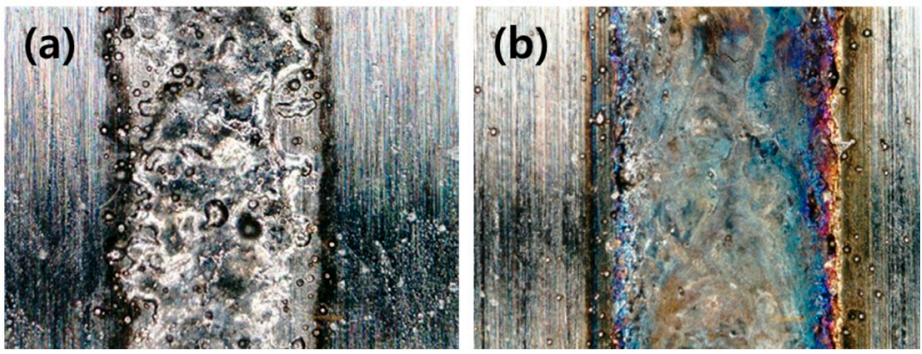

Figure 11. Single-tracks of different conditions between (a) incomplete single-track and (b) good single-track [97].

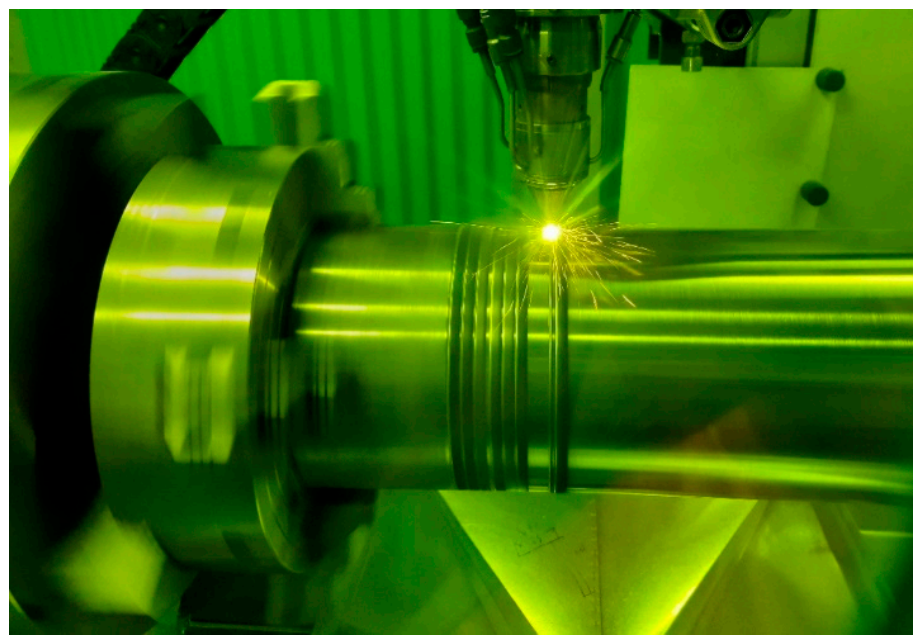

Figure 12. Photograph of a thin-DED test on a roller.

\section{Summary}

In thin-DED processes, nanoparticle fumes and massive agglomerated-spatter can be released when the base metal is heated at the focus to form a melt pool, which is collectively called evaporation products. Evaporation products can be prevented by selecting suitable powder and source laser, further finely optimizing process parameters. To prevent evaporation products in thin-DED, especially the following factors were investigated:

(1) To reduce the evaporation products, it is first necessary to suppress the concentration of the needle-like laser energy. Particularly a continuous wave laser, top-hat mode, and rectangular beam are more desirable than a pulsed laser or Gaussian beam.

(2) The defocus shifts the laser beam focus, widening the laser irradiation area and lowering the energy density.

(3) Fine particles with a size of less than five micrometers can form fumes easily. Powders with an average size of 30-45 micrometers are suitable in thin-DED.

(4) It is necessary to minimize carbon or boron and low evaporation point components. A sintered powder with a porous surface generates evaporation products because of high moisture adsorption and laser absorption in the air. Therefore, atomized powders and plasma atomized carbide powders with smooth surfaces are preferred for thin-DED.

(5) The bonding zone can be thinner by feeding the powder slightly above the focus to lower the laser energy density delivered to the melt pool. Powder recovery and nozzle scanning velocity can also be increased.

Author Contributions: K.-H.K. contributed primarily to writing the original draft and compiled the manuscript and the data collection; C.-H.J. contributed to writing, drawing, and data curation; D.-Y.J. contributed to writing-outline of the paper, reviewing and editing, supervision; S.-K.H. administrated a work, conceptualization, reviewing and editing the manuscript. All authors have read and agreed to the published version of the manuscript. 
Funding: This research received no external funding.

Data Availability Statement: Not applicable.

Acknowledgments: The authors appreciate the financial support for this work from Inha University.

Conflicts of Interest: The authors declare no conflict of interest.

\section{References}

1. Baruthio, F. Toxic effects of chromium and its compounds. Biol. Trace Element Res. 1992, 32, 145-153. [CrossRef]

2. Sun, H.; Brocato, J.; Costa, M. Oral Chromium Exposure and Toxicity. Curr. Environ. Health Rep. 2015, 2, 295-303. [CrossRef] [PubMed]

3. Kim, F.H.; Moylan, S.P. Literature review of metal additive manufacturing defects. In Literature Review of Metal Additive Manufacturing Defects; National Institute of Standards and Technology (NIST): Gaithersburg, MD, USA, 2018.

4. Gaja, H.; Liou, F. Defects monitoring of laser metal deposition using acoustic emission sensor. Int. J. Adv. Manuf. Technol. 2016, 90, 561-574. [CrossRef]

5. Tammas-Williams, S.; Withers, P.J.; Todd, I.; Prangnell, P.B. The Influence of Porosity on Fatigue Crack Initiation in Additively Manufactured Titanium Components. Sci. Rep. 2017, 7, 1-13. [CrossRef] [PubMed]

6. Zhang, B.; Li, Y.; Bai, Q. Defect Formation Mechanisms in Selective Laser Melting: A Review. Chin. J. Mech. Eng. 2017, 30, 516-520. [CrossRef]

7. Zai, L.; Zhang, C.; Wang, Y.; Guo, W.; Wellmann, D.; Tong, X.; Tian, Y. Laser Powder Bed Fusion of Precipitation-Hardened Martensitic Stainless Steels: A Review. Metals 2020, 10, 255. [CrossRef]

8. Dass, A.; Moridi, A. State of the Art in Directed Energy Deposition: From Additive Manufacturing to Materials Design. Coatings 2019, 9, 418. [CrossRef]

9. Everton, S.K.; Hirsch, M.; Stravroulakis, P.; Leach, R.K.; Clare, A.T. Review of in-situ process monitoring and in-situ metrology for metal additive manufacturing. Mater. Des. 2016, 95, 431-445. [CrossRef]

10. Kirichenko, K.Y.; Agoshkov, A.I.; Drozd, V.A.; Gridasov, A.V.; Kholodov, A.S.; Kobylyakov, S.P.; Kosyanov, D.Y.; Zakha-Renko, A.M.; Karabtsov, A.A.; Shimanskii, S.R.; et al. Charac-terization of fume particles generated during arc welding with various covered electrodes. Sci. Rep. 2018, 8, 1-7. [CrossRef]

11. Zhang, M.; Chen, G.; Zhou, Y.; Li, S.; Deng, H. Observation of spatter formation mechanisms in high-power fiber laser welding of thick plate. Appl. Surf. Sci. 2013, 280, 868-875. [CrossRef]

12. Nakamura, H.; Kawahito, Y.; Nishimoto, K.; Katayama, S. Elucidation of melt flows and spatter formation mechanisms during high power laser welding of pure titanium. J. Laser Appl. 2015, 27, 032012. [CrossRef]

13. Popescu, A.; Delval, C.; Shadman, S.; Leparoux, M. Investigation and in situ removal of spatter generated during laser ablation of aluminium composites. Appl. Surf. Sci. 2016, 378, 102-113. [CrossRef]

14. Zeidler-Erdely, P.C.; Erdely, A.; Antonini, J.M. Immunotoxicology of arc welding fume: Worker and experimental animal studies. J. Immunotoxicol. 2012, 9, 411-425. [CrossRef] [PubMed]

15. Harris, M.K. Welding Health and Safety: A Field Guide for OEHS Professionals; AIHA Press: Fairfax, VA, USA, $2002 ;$ pp. $201-222$.

16. Zimmer, A.T. The Influence of Metallurgy on the Formation of Welding Aerosols. J. Environ. Monit. 2002, 4, 628-632. [CrossRef]

17. Antonini, J.M. Health effects associated with welding. In Comprehensive Materials Processing; Hashmi, S., Batalha, G.F., Tyne, C.J.V., Yilbas, B., Eds.; Elsevier: Oxford, UK, 2014; pp. 54-66.

18. Anisimov, S.I. Vaporization of Metal Absorbing Laser Radiation. J. Exp. Theor. Phys. 1968, 27, 182. Available online: http: //www.jetp.ac.ru/cgi-bin/dn/e_027_01_0182.pdf (accessed on 21 December 2020). [CrossRef]

19. Anisimov, S.I.; Khokhlov, V.A. Instabilities in Laser-Matter Interaction; CRC Press: Boca Raton, FL, USA, $1995 ;$ p. 16.

20. Noorbatcha, I.; Lucchese, R.R.; Zeiri, Y. Effects of gas-phase collisions on particles rapidly desorbed from surfaces. Phys. Rev. B 1987, 36, 4978-4981. [CrossRef] [PubMed]

21. Kelly, R.; Miotello, A. On the mechanisms of target modification by ion beams and laser pulses. Nucl. Instrum. Methods Phys. Res. Sect. B 1997, 122, 374-400. [CrossRef]

22. Thum-Jager, A.; Rohr, K. Angular emission distributions of neutrals and ions in laser ablated particle beams. J. Phys. D Appl. Phys. 1999, 32, 2827-2831. [CrossRef]

23. Kelly, R. On the dual role of the Knudsen layer and unsteady, adiabatic expansion in pulse sputtering phenomena. J. Chem. Phys. 1990, 92, 5047-5056. [CrossRef]

24. Saenger, K.L. On the origin of spatial nonuniformities in the composition of pulsed-laser-deposited films. J. Appl. Phys. 1991, 70, 5629-5635. [CrossRef]

25. Sibold, D.; Urbassek, H.M. Kinetic study of pulsed desorption flows into vacuum. Phys. Rev. A 1991, 43, 6722-6734. [CrossRef] [PubMed]

26. Urbassek, H.M.; Sibold, D. Gas-phase segregation effects in pulsed laser desorption from binary targets. Phys. Rev. Lett. 1993, 70, 1886-1889. [CrossRef] [PubMed]

27. Kools, J.C.S. Monte Carlo simulations of the transport of laser-ablated atoms in a diluted gas. J. Appl. Phys. 1993, 74, 6401-6406. [CrossRef] 
28. Anisimov, S.I.; Bäuerle, D.; Luk'yanchuk, B.S. Gas dynamics and film profiles in pulsed-laser deposition of materials. Phys. Rev. B 1993, 48, 12076-12081. [CrossRef]

29. Bird, G.A. Molecular Gas Dynamics and the Direct Simulation of Gas Flows; Clarendon Press: Oxford, UK, 1994 ; pp. $218-256$.

30. Bulgakov, A.V.; Bulgakova, N.M. Dynamics of laser-induced plume expansion into an ambient gas during film deposition. J. Phys. D Appl. Phys. 1995, 28, 1710-1718. [CrossRef]

31. Leboeuf, J.N.; Chen, K.R.; Donato, J.M.; Geohegan, D.B.; Liu, C.L.; Puretzky, A.A.; Wood, R.F. Modeling of plume dynamics in laser ablation processes for thin film deposition of materials. Phys. Plasmas 1996, 3, 2203-2209. [CrossRef]

32. Wood, R.F.; Chen, K.R.; Leboeuf, J.N.; Puretzky, A.A.; Geohegan, D.B. Dynamics of Plume Propagation and Splitting during Pulsed-Laser Ablation. Phys. Rev. Lett. 1997, 79, 1571-1574. [CrossRef]

33. Itina, T.E.; Marine, W.; Autric, M. Monte Carlo simulation of pulsed laser ablation from two-component target into diluted ambient gas. J. Appl. Phys. 1997, 82, 3536-3542. [CrossRef]

34. Ready, J.F. Industrial Applications of Lasers, 2nd ed.; Academic Press: New York, NY, USA, 1997; pp. $320-331$.

35. Bulgakov, A.V.; Bulgakova, N.M. Gas-dynamic effects of the interaction between a pulsed laser-ablation plume and the ambient gas: Analogy with an underexpanded jet. J. Phys. D Appl. Phys. 1998, 31, 693-703. [CrossRef]

36. Garrelie, F.; Catherinot, A. Monte Carlo simulation of the laser-induced plasma-plume expansion under vacuum and with a background gas. Appl. Surf. Sci. 1999, 138, 97-101. [CrossRef]

37. Zhigilei, L.V.; Garrison, B. Molecular dynamics simulation study of the fluence dependence of particle yield and plume composition in laser desorption and ablation of organic solids. Appl. Phys. Lett. 1999, 74, 1341-1343. [CrossRef]

38. Garrelie, F.; Champeaux, C.; Catherinot, A. Expansion dynamics of the plasma plume created by laser ablation in a background gas. Appl. Phys. A Mater. Sci. Process. 1999, 69, S55-S58. [CrossRef]

39. Arnold, N.; Gruber, J.; Heitz, J. Spherical expansion of the vapor plume into ambient gas: An analytical model. Appl. Phys. A 1999, 69, S87-S93. [CrossRef]

40. Gusarov, A.V.; Gnedovets, A.G.; Smurov, I. Gas dynamics of laser ablation: Influence of ambient atmosphere. J. Appl. Phys. 2000, 88, 4352. [CrossRef]

41. Le, H.C.; Zeitoun, D.E.; Parisse, J.D.; Sentis, M.; Marine, W. Modeling of gas dynamics for a laser-generated plasma: Propa-gation into low-pressure gases. Phys. Rev. E 2000, 62, 4152-4161. [CrossRef]

42. Ivanov, D.S.; Zhigilei, L.V. Combined atomistic-continuum modeling of short-pulse laser melting and disintegration of metal films. Phys. Rev. B 2003, 68, 1-12. [CrossRef]

43. Itina, T.E.; Gouriet, K.; Zhigilei, L.V.; Noël, S.; Hermann, J.; Sentis, M. Mechanisms of small clusters production by short and ultra-short laser ablation. Appl. Surf. Sci. 2007, 253, 7656-7661. [CrossRef]

44. Itina, T.; Voloshko, A. Nanoparticle formation by laser ablation in air and by spark discharges at atmospheric pressure. Appl. Phys. A 2013, 113, 473-478. [CrossRef]

45. Klassen, A.; Scharowsky, T.; Körner, C. Evaporation model for beam based additive manufacturing using free surface lattice Boltzmann methods. J. Phys. D Appl. Phys. 2014, 47, 1-12. [CrossRef]

46. Stauss, S.; Urabe, K.; Muneoka, H.; Terashima, K. Pulsed laser ablation in high-pressure gases, pressurized liquids and supercritical fluids: Generation, fundamental characteristics and applications. In Applications of Laser Ablation-Thin Film Deposition, Nanomaterial Synthesis and Surface Modification; IntechOpen: London, UK, 2016; pp. 223-238.

47. Stauss, S.; Terashima, K. Diamondoids: Synthesis, Properties, and Applications; Pan Stanford Publishing: Singapore, $2017 ;$ p. 159. [CrossRef]

48. Sakka, T.; Masai, S.; Fukami, K.; Ogata, Y.H. Spectral profile of atomic emission lines and effects of pulse duration on laser ablation in liquid. Spectrochim. Acta Part B 2009, 64, 981-985. [CrossRef]

49. Lam, J.; Amans, D.; Chaput, F.; Diouf, M.; LeDoux, G.; Mary, N.; Masenelli-Varlot, K.; Motto-Ros, V.; Dujardin, C. $\gamma-\mathrm{Al}_{2} \mathrm{O}_{3}$ nanoparticles synthesised by pulsed laser ablation in liquids: A plasma analysis. Phys. Chem. Chem. Phys. 2014, 16, 963-973. [CrossRef]

50. Ibrahimkutty, S.; Wagener, P.; Rolo, T.D.S.; Karpov, D.; Menzel, A.; Baumbach, T.; Barcikowski, S.; Plech, A. A hierarchical view on material formation during pulsed-laser synthesis of nanoparticles in liquid. Sci. Rep. 2015, 5, 16313. [CrossRef]

51. Muneoka, H.; Himeno, S.; Urabe, K.; Stauss, S.; Baba, M.; Suemoto, T.; Terashima, K. Dynamics of cavitation bubbles formed by pulsed-laser ablation plasmas near the critical point of $\mathrm{CO}_{2}$. J. Phys. D Appl. Phys. 2018, 52, 025201. [CrossRef]

52. Chaudhary, K.; Rizvi, S.Z.H.; Ali, J. Laser-induced plasma and its applications. In Plasma Science and Technology: Progress in Physical States and Chemical Reactions; Mieno, T., Ed.; InTech: London, UK, 2016; p. 264. [CrossRef]

53. Dahotre, N.B.; Harimkar, S.P. Laser Fabrication and Machining of Materials; Springer: New York, NY, USA, 2008 ; pp. 123-130.

54. Zhou, J.; Tsai, H.; Wang, P. Hybrid laser-arc welding of aerospace and other materials. In Welding and Joining of Aerospace Materials; Elsevier: Oxford, UK, 2012; pp. 109-141.

55. Kim, K.R.; Farson, D.F. $\mathrm{CO}_{2}$ laser-plume interaction in materials processing. J. Appl. Phys. 2001, 89, 681-688. [CrossRef]

56. Padilla-Martinez, J.P.; Berrosperodriguez, C.; Aguilar, G.; Ramirez-San-Juan, J.C.; Ramos-Garcia, R. Optic cavitation with CW lasers: A review. Phys. Fluids 2014, 26, 122007. [CrossRef]

57. Rekhi, S.; Tempere, J.; Silvera, I.F. Temperature determination for nanosecond pulsed laser heating. Rev. Sci. Instrum. 2003, 74, 3820. [CrossRef] 
58. Hendricks, L.J.; Zobrist, S.P. Measurement of the radial temperature distribution of the heated spot produced by a focused laser beam using an optical pyrometer. Appl. Opt. 1981, 20, 1880-1883. [CrossRef]

59. Khairallah, S.A.; Anderson, A.T.; Rubenchik, A.; King, W.E. Laser powder-bed fusion additive manufacturing: Physics of complex melt flow and formation mechanisms of pores, spatter, and denudation zones. Acta Mater. 2016, 108, 36-45. [CrossRef]

60. Hooper, P.A. Melt pool temperature and cooling rates in laser powder bed fusion. Addit. Manuf. 2018, 22, 548-559. [CrossRef]

61. Migliore, L. Laser Materials Processing; Marcel Dekker: New York, NY, USA, 1996; pp. 65-83.

62. Gunenthiram, V.; Peyre, P.; Schneider, M.; Dal, M.; Coste, F.; Koutiri, I.; Fabbro, R. Experimental analysis of spatter generation and melt-pool behavior during the powder bed laser beam melting process. J. Mater. Process. Technol. 2018, 251, 376-386. [CrossRef]

63. Madrid, J.; Lorin, S.; Söderberg, R.; Hammersberg, P.; Wärmefjord, K.; Lööf, J. A Virtual Design of Experiments Method to Evaluate the Effect of Design and Welding Parameters on Weld Quality in Aerospace Applications. Aerospace 2019, 6, 74. [CrossRef]

64. Niu, C.; Zhu, T.; Lv, Y. Influence of Surface Morphology on Absorptivity of Light-Absorbing Materials. Int. J. Photoenergy 2019, 2019, 1476217. [CrossRef]

65. He, X.C.; Mazumder, J. Transport phenomena during direct metal deposition. J. Appl. Phys. 2007, 101, 053113. [CrossRef]

66. Dickson, L.D. Characteristics of a Propagating Gaussian Beam. Appl. Opt. 1970, 9, 1854-1861. [CrossRef]

67. Engström, H. Theoretical and Practical Aspects of Laser Cladding. Licentiate Thesis, Luleå University of Technology, Luleå, Sweden, April 1996; pp. 2-14. Available online: https://www.diva-portal.org/smash/get/diva2:990813/FULLTEXT01.pdf (accessed on 23 December 2020).

68. Heiple, C.R.; Roper, J.R.; Stagner, R.T.; Aden, R.J. Surface Active Element Effects on the Shape of GTA, Laser, and Electron Beam Welds. Weld. J. 1983, 62, 72-77. Available online: https://app.aws.org/wj/supplement/WJ_1983_03_s72.pdf (accessed on 23 December 2020).

69. Li, S.; Chen, G.; Katayama, S.; Zhang, Y. Relationship between spatter formation and dynamic molten pool during high-power deep-penetration laser welding. Appl. Surf. Sci. 2014, 303, 481-488. [CrossRef]

70. Katayama, S. Handbook of Laser Welding Technologies; Elsevier: Oxford, UK, 2013; pp. 7-9.

71. Astrath, N.G.C.; Astrath, F.B.G.; Shen, J.; Zhou, J.; Gu, C.E.; Malacarne, L.C.; Pedreira, P.R.B.; Bento, A.C.; Baesso, M.L. Top-hat cw laser induced thermal mirror: A complete model for material characterization. Appl. Phys. A 2008, 94, 473-481. [CrossRef]

72. Laserline Optics Canada. Powell Lens Buyer's Guide. Available online: https://www.laserlineoptics.com/powell_primer.html (accessed on 23 December 2020).

73. Dowden, J.; Schulz, W. The Theory of Laser Materials Processing: Heat and Mass Transfer in Modern Technology, 2nd ed.; Springer: Cham, Switzerland, 2017; pp. 92-109.

74. Yeo, C.; Tam, S.; Jana, S.; Lau, M.W. A technical review of the laser drilling of aerospace materials. J. Mater. Process. Technol. 1994, 42, 15-49. [CrossRef]

75. Javan, N.S.; Homami, S.H.H. Nonlinear modes of an intense laser beam interacting with a periodic lattice of nanoparticle. Phys. Plasmas 2015, 22, 82311. [CrossRef]

76. Karlovets, D.V. Electron with orbital angluar momentum in a strong laser wave. Phys. Rev. A 2012, 86, 1-12. [CrossRef]

77. Lawrence, J.; Pou, J.; Low, D.K.Y.; Toyserkani, E. Advances in Laser Materials Processing; Woodhead Publicing Limited: Great Abington, Cambridge, UK, 2010; p. 3.

78. Fuerschbach, P.W.; Norris, J.T.; He, X.; DebRoy, T. Understanding Metal Vaporization from Laser Welding; Sandia National Laboratories: Livemore, CA, USA, 2003; p. 39. Available online: https://digital.library.unt.edu/ark:/67531/metadc886946/m2/1 /high_res_d/918266.pdf (accessed on 23 December 2020).

79. Rudy, E. Ternary Phase Equilibria in Transition Metal-Boron-Carbon-Silicon System, Part V, Compendium of Phase Diagram Data; Tech. Rep. AFML-TR-65-2; AFML (Air Force Systems Command), Wright-Patterson Air Force Base: Dayton, OH, USA, 1969; pp. 179-180. Available online: https:/ /apps.dtic.mil/dtic/tr/fulltext/u2/664345.pdf (accessed on 23 December 2020).

80. Venkatraman, M.; Neumann, J.P. The C-Cr (Carbon-Chromium) System. Bull. Alloy Phase Diagr. 1990, 11, 152-159. [CrossRef]

81. Berdnikov, V.I.; Gudim, Y.A. Analysis of the thermodynamic properties of condensed carbides. Steel Transl. 2012, 42, 477-482. [CrossRef]

82. Vlasova, M.; Kakazey, M.; Mel’Nikov, I.; Reséndiz-González, M.; Fironov, Y.; Ryabtsev, D.; Kondrashenko, S. Formation of $\mathrm{Cr}_{\mathrm{x}} \mathrm{C}_{\mathrm{y}} \mathrm{O}_{\mathrm{z}}$ coatings under laser ablation of $\mathrm{Cr}_{23} \mathrm{C}_{6}$ ceramics. Surf. Coat. Technol. 2018, 349, 93-102. [CrossRef]

83. Franke, P.; Neuschütz, D. Landolt-Börnstein-Group IV Physical Chemistry. Binary Systems. Part 2: Elements and Binary Systems from $B-C$ to $C r-Z r C o-W$; Springer: Berlin/Heidelberg, Germany, 2004; p. 115.

84. Wieczerzak, K.; Bala, P.; Stępień, M.; Cios, G.; Kozieł, T. The Characterization of Cast Fe-Cr-C Alloy. Arch. Met. Mater. 2015, 60, 779-782. [CrossRef]

85. Pierson, H.O. Handbook of Refractory Carbides and Nitrides; Noyes Publications: Saddle River, NJ, USA, $1996 ;$ p. 44.

86. Upadhyaya, G. Materials science of cemented carbides-An overview. Mater. Des. 2001, 22, 483-489. [CrossRef]

87. Korzhyk, V.; Kulak, L.; Shevchenko, V.; Kvasnitskiy, V.; Kuzmenko, N.; Liu, X.; Cai, Y.X.; Wang, L.; Xie, H.; Zou, L. New Equipment for Production of Super Hard Spherical Tungsten Carbide and other High-Melting Compounds Using the Method of Plasma Atomization of Rotating Billet. Mater. Sci. Forum 2017, 898, 1485-1497. [CrossRef] 
88. Baskoro, A.S.; Supriadi, S.; Dharmanto, D. Review on Plasma Atomizer Technology for Metal Powder, Proceedings of the MATEC Web of Conferences 269, Bali, Indonesia, 15-20 July 2018; EDP Sciences: Les Ulis, France, 2019; pp. 1-9. Available online: https:/ / www.matec-conferences.org/articles/matecconf/pdf/2019/18/matecconf_iiw18_05004.pdf (accessed on 23 December 2020). [CrossRef]

89. Shevchenko, R.A.; Vakhrushin, A.Y.; Chukanov, A.P. Manufacture of Tungsten Monocarbide (WC) Spherical Powder. U.S. Patent Application No. 20190300374A1, 3 October 2019.

90. Shin, D.; Swain, B.; Han, C.; Kim, Y.; Lee, C.-G.; Park, K.-S. Comparison of different tungsten precursors for preparation of tungsten nanopowder by RF induction thermal plasma. Int. J. Refract. Met. Hard Mater. 2020, 86, 104995. [CrossRef]

91. Oerlikon Metco. Thermal Spray Materials Guide 2017; Oerlikon Metco: Pfäffikon, Switzerland, 2018; p. 6. Available online: https:/ / www.oerlikon.com/ecomaXL/files/oerlikon_BRO-0001.17_TS_MaterialGuide_EN.pdf (accessed on 24 December 2020).

92. Evans, J.R.G.; Edirisinghe, M.J. Interfacial factors affecting the incidence of defects in ceramic mouldings. J. Mater. Sci. 1991, 26, 2081-2088. [CrossRef]

93. Navrotsky, A.; Ma, C.; Lilova, K.; Birkner, N. Nanophase Transition Metal Oxides Show Large Thermodynamically Driven Shifts in Oxidation-Reduction Equilibria. Science 2010, 330, 199-201. [CrossRef] [PubMed]

94. Shankar, P.; Rayappan, J.B.B. Gas sensing mechanism of metal oxides: The role of ambient atmosphere, type of semiconductor and gases-A review. Sci. Lett. J. 2015, 4, 126.

95. Fine, G.F.; Cavanagh, L.M.; Afonja, A.; Binions, R. Metal Oxide Semi-Conductor Gas Sensors in Environmental Monitoring Sensors 2010, 10, 5469-5502. [CrossRef]

96. Shanefield, D.J. Organic Additives and Ceramic Processing: With Applications in Powder Metallurgy, Ink, and Paint; Springer Science and Business Media: New York, NY, USA, 1995; p. 139.

97. Kim, K.-H.; Jung, C.-H.; Jeong, D.-Y.; Hyun, S.-K. Causes and Measures of Fume in Directed Energy Deposition: A Review. Korean J. Met. Mater. 2020, 58, 383-396. [CrossRef]

98. Sahoo, P.; Collur, M.M.; Debroy, T. Effects of oxygen and sulfur on alloying element vaporization rates during laser welding. Met. Mater. Trans. A 1988, 19, 967-972. [CrossRef]

99. Dong, W.; Kokawa, H.; Sato, Y.S.; Tsukamoto, S.; Ogawa, M. Mechanism governing nitrogen absorption by steel weld metal during laser welding. Met. Mater. Trans. A 2004, 35, 331-338. [CrossRef]

100. Ribic, B.; Tsukamoto, S.; Rai, R.; Debroy, T. Role of surface-active elements during keyhole-mode laser welding. J. Phys. D Appl. Phys. 2011, 44, 485203. [CrossRef]

101. Markwalder, B.; Gozel, P.; Bergh, H.V.D. Laser-induced temperature jump measurements in the kinetics of association and dissociation of the nitrogen oxide $\left(\mathrm{N}_{2} \mathrm{O}_{3}\right)+\mathrm{M}=$ nitrogen dioxide + nitrous oxide + M system. J. Phys. Chem. 1993, 97, 5260-5265. [CrossRef]

102. Springer, H.; Baron, C.; Szczepaniak, A.; Jägle, E.; Wilms, M.; Weisheit, A.; Raabe, D. Efficient additive manufacturing production of oxide- and nitride-dispersion-strengthened materials through atmospheric reactions in liquid metal deposition. Mater. Des. 2016, 111, 60-69. [CrossRef]

103. Liu, K.; Song, D.; Azarm, A.; Chin, S.; Kong, F. Neutral Dissociation of Superexcited Nitic Oxide Induced by Intense Laser Fields. Chin. J. Chem. Phys. 2010, 23, 252-254. [CrossRef]

104. Hozoorbakhsh, A.; Ismail, M.I.S.; Aziz, N.B.A. A computational analysis of heat transfer and fluid flow in high-speed scanning of laser micro-welding. Int. Commun. Heat Mass Transf. 2015, 68, 178-187. [CrossRef]

105. Powell, J. Laser Cladding. Ph.D. Thesis, University of London, London, UK, 1983; pp. 105-108. Available online: https: //spiral.imperial.ac.uk/bitstream/10044/1/8117/1/JohnPowell-1983-PhD-Thesis.pdf (accessed on 23 December 2020).

106. Kunimine, T.; Miyazaki, R.; Yamashita, Y.; Funada, Y. Effects of Laser-Beam Defocus on Microstructural Features of Compositionally Graded WC/Co-Alloy Composites Additively Manufactured by Multi-Beam Laser Directed Energy Deposition. Sci. Rep. 2020, 10, 8975. [CrossRef]

107. Efficient Transformation of Gaussian Beams into Uniform, Rectangular Intensity Distributions (Brochure of Coherent). Available online: https:/ / www.coherent.com/assets/pdf/Efficient-Transformation-of-Gaussian-Beams-into-Uniform-RectangularIntensity-Distributions_FORMFIRST.pdf (accessed on 23 December 2020).

108. Cheng, Y.; Cui, R.; Wang, H.; Han, Z. Effect of processing parameters of laser on microstructure and properties of cladding 42CrMo steel. Int. J. Adv. Manuf. Technol. 2018, 96, 1715-1720. [CrossRef]

109. Kar, A.; Scott, J.E.; Latham, W.P. Effects of mode structure on three-dimensional laser heating due to single or multiple rectangular laser beams. J. Appl. Phys. 1996, 80, 673. [CrossRef]

110. Chen, S.; Li, L.; Chen, Y.; Dai, J.; Huang, J. Improving interfacial reaction nonhomogeneity during laser welding-brazing aluminum to titanium. Mater. Des. 2011, 32, 4408-4416. [CrossRef]

111. Wang, Y.; Shi, J. Developing very strong texture in a nickel-based superalloy by selective laser melting with an ultra-high power and flat-top laser beam. Mater. Charact. 2020, 165, 110372. [CrossRef]

112. Wautelet, M. Laser-Assisted Reaction of Metals with Oxygen. Appl. Phys. A 1990, 50, 131-139. [CrossRef]

113. Uusitalo, M.A.; Vuoristo, P.M.J.; Mäntylä, T.A. High temperature corrosion of coatings and boiler steels in oxidizing chlorinecontaining atmosphere. Mater. Sci. Eng. A 2003, 346, 168. [CrossRef]

114. Haanappel, V.A.C.; Fransen, T.; Gellings, P.J. Chlorine-Induced High Temperature Corrosion: I. Metals and Alloys-A Review. High Temp. Mater. Process. 1992, 10, 82. [CrossRef] 
115. De Young, R.J.; Barnes, N.P. Profiling atmospheric water vapor using a fiber laser lidar system. Appl. Opt. 2010, $49,562-567$. [CrossRef] [PubMed]

116. Boehm, H.P. Free radicals and graphite. Carbon 2012, 50, 3154-3157. [CrossRef]

117. He, Y.; Liu, S.; Priest, C.; Shi, Q.; Wu, G. Atomically dispersed metal-nitrogen-carbon catalysts for fuel cells: Advances in catalyst design, electrode performance, and durability improvement. Chem. Soc. Rev. 2020, 49, 3510. [CrossRef]

118. Luo, Y.W.; Guo, H.J.; Sun, X.L.; Guo, J. Influence of the Nitrogen Content on the Carbide Transformation of AISI M42 High-Speed Steels during Annealing. Sci. Rep. 2018, 8, 4328. [CrossRef]

119. Kolsch, N.; Seidel, A.; Finaske, T.; Brueckner, F.; Gumpinger, J.; Bavdaz, M.; Rohr, T.; Ghidini, T.; Leyens, C. Novel local shielding approach for the laser welding based additive manufacturing of large structural space components from titanium. J. Laser Appl. 2020, 32, 022075. [CrossRef]

120. Patalas-Maliszewska, J.; Feldshtein, E.; Devojno, O.; Sliwa, M.; Kardapolava, M.; Lutsko, N. Single-tracks as a Key Factor in Additive Manufacturing Technology-Analysis of Research Trends and Metal Deposition Behavior. Materials 2020, $13,1115$. [CrossRef] 